\title{
Structural and Optical studies of Traditional Indian Medicine: Kajjali \& Narikela Lavan
}

\author{
Balkrishan Acharya', Mishra Nayan², Hira Narinder Kaur ${ }^{3}$, Yadav Shailendra ${ }^{4}$, Manikyam Hemanth Kumar ${ }^{5}$, Chaudhary Ritu ${ }^{6}$ \\ 'Department of Research \& Development, University of Patanjali, Haridwar, Uttarakhand, INDIA. \\ 2Department of Research \& Development, Analytical Scientist, Patanjali Natural Coloroma (P) Ltd, Padartha, Haridwar, Uttarakhand, INDIA \\ ${ }^{3}$ Department of Research \& Development, Research Scientist, Patanjali Natural Coloroma (P) Ltd, Padartha, Haridwar, Uttarakhand, INDIA. \\ ${ }^{4}$ Department of Rasa-Shastra \& Bhaishajya kalpana, S.N.K. Ayurvedic Medical College, Chandaus, Aligarh, Uttar Pradesh, INDIA. \\ ${ }^{5}$ Department of Research \& Development, Research Head, Patanjali Natural Coloroma (P) Ltd, Padartha, Haridwar, Uttarakhand, INDIA. \\ ${ }^{6}$ Department of Quality Control, Quality Control Incharge, Patanjali Natural Coloroma (P) Ltd, Padartha, Haridwar, Uttarakhand, INDIA.
}

\begin{abstract}
Background: Traditional Indian system of medicine (Ayurveda) has its existence since ages but it is lacking characterization of drugs with the help of advanced techniques. It can help this system to find its place in today's world scenario. Objective: The present study aims to characterize Kajjali and Narikela Lavana, which are highly effective \& most common Indian traditional medicines. Materials and Methods: These traditional medicines have been characterized using grazing angle X-ray diffraction (GAXRD), Scanning electron microscopy (SEM), Optical absorption and Photo luminescence spectroscopy. Result and Discussion: It is shown that the luminescence emission band can be considerably narrowed and PL intensity can be considerably enhanced in meta-cinnabar ( $\beta$-HgS) or Kajjali cubic crystal structure. Moreover, the emission photon energy has been shown to shift simply by changing the size of Kajjali particle. Conclusion: These herbo-mineral drugs are conceived to be more effectual than any other healing systems because these nanocrystalline drugs
\end{abstract}

can enter into the blood stream and are more biocompatible as compared to any chemically prepared entity, similar to biologically prepared nanoparticles. Recommendations: The effectiveness of Kajjali and Narikela Lavana can be further justified with the help of experimental and clinical studies.

Key words: Grazing angle X-ray diffraction, Indian Traditional medicine, Kajjali, Luminesce, Narikel Lavan, Scanning electron microscopy.

Correspondence :

Dr. Narinder Kaur Hira,

Department of Research \& Development, Patanjali Natural Coloroma (P) Ltd, Padartha, Haridwar-249404, INDIA.

Phone no: 8192845958

E-mail: nkaur28@yahoo.com

DOI: 10.5530/jyp.2016.4.29

\section{INTRODUCTION}

Although Indian traditional system of medicine being the quondam system of health care, yet its acceptance is parochial to south-east Asia only, especially in India. ${ }^{1}$ It has to cover a long distance to find its place in modern world. In last five decades, good percentage of literary research has been done in this field and further requirement is to develop new strategies for research while keeping in mind the bedrocks of Indian traditional system of medicine. ${ }^{2}$ Moreover, implementation of 'Pharmacovigilance' in Ayurveda plays an important role in optimizing drug safety and improving treatment outcomes. ${ }^{3}$

The traditional literature of medicine (Ayurveda) is overflowing with the treasure of several herbal as well as herbo-mineral preparations. Narikela Lavan and Kajjali, both are herbo-mineral compounds delineated in various classical Ayurvedic texts. Narikela Lavan consists of two ingredients- Narikela and Saindhava Lavan. Narikela is the sanskrit name of coconut (Cocus nucifera linn) and that of Saindhava lavan is rock salt (Sodi chloridium). Coconut is a drug of plant origin and rock salt is from mineral origin. Thus, Narikela lavan is a herbomineral preparation. Coconut (Cocus nucifera linn.) belongs to the family Arecaceae (palm family). It is a vast family having around 217 genera and 2500 species. Cocos nucifera belongs to the order arecales and it is the only species of the genus cocos belonging to the subfamily cocoideae, which has 27 genera, and 600 species. ${ }^{4}$ Five different types of salts are mainly used in several Ayurvedic preparations. Most commonly used and best form among them is Saindhava Lavan. It is a mineral that is composed chiefly of sodium chloride. Chloride and sodium ions are the two major elements of salt. ${ }^{5}$

Kajjali is a commixture of mercury and sulphur in varing ratios. The impotance of kajjali lies in the facts that mercury cannot be consumed in its natural form and also it is very difficult to convert mercury into powder form in atmospheric conditions. Therefore, kajjali forms the basic component of maximum herbo-mineral formulations. It gives the structural and functional stability to the formulations. ${ }^{6}$

\section{MATERIALS AND METHODS}

\section{Synthesis Procedure}

Narikela Lavan- Mature fruit of coconut was taken and its outer fibers were removed. A hole was through an eye of the coconut and its water was removed completely. Then finely powdered rock salt was filled into it through the eye only. The hole was then sealed with mud and whole of the coconut was covered with the layer of thin cotton cloth impregnated with mud. When dry, it was subjected to the heat of around $1000^{\circ} \mathrm{C}$ temperature in a pit full of cow-dung cakes. In this way, a grayish black coloured ash of coconut and rock salt is obtained. This ash is known as Narikela Lavan which is used as enhancer of digestive power and cures hyperacidity. The temperature at which this formulation is prepared, activated charcoal is formed. ${ }^{7}$ Activated charcoal reduces the absorption of toxins and various drugs such as aspirin, acetaminophen, phenobarbital, phenytoin, digoxin from the gastrointestinal tract. It also increases the clearance of already absorbed drugs from the circulation. ${ }^{8}$

Kajjali- Before preparing kajjali, the detoxification of mercury and sulphur are required. Therefore, the purification of mercury is done by triturating with lime powder initially and then with equal amount of paste of Allium sativum along with half the amount of rock salt. ${ }^{9}$ Sulphur is purified by cow's milk. Then both of them were mixed in equal quantity and triturated with the help of mortar-pestle. Gradually, the mixture converts into black powder. Trituration was performed until the complete disappearance of shining of powder. The pressure applied during 
Table 1: Indexed X-ray powder diffraction data along with the calculated lattice parameters and d values of Narikel lavan or $\mathrm{NaCl}$ FCC

\begin{tabular}{ccccccc}
\hline Peak & 2Theta & d-spacing (Å) & I/I0 & h k I & Lattice Parameters (Å) & Size $(\AA)$ \\
\hline 1 & 27.38 & 3.25 & 2.5 & 111 & 5.638 & \\
2 & 31.72 & 2.82 & 100.0 & 200 & 5.638 & 520 \\
3 & 45.47 & 1.99 & 16.8 & 220 & 5.640 & \\
4 & 56.49 & 1.63 & 3.2 & 222 & 5.638 & \\
5 & 66.24 & 1.41 & 1.8 & 331 & 5.637 & \\
\hline
\end{tabular}

\begin{tabular}{|c|c|c|c|c|c|c|}
\hline Peak & 2Theta & d-spacing $(\AA ̊)$ & $1 / 10$ & h kl & Lattice Parameters (Å) & $\operatorname{Size}(\AA \AA)$ \\
\hline 1 & 26.27 & 3.39 & 100 & 111 & 5.854 & 370 \\
\hline 2 & 30.36 & 2.94 & 21.1 & 200 & 5.853 & 365 \\
\hline 3 & 43.48 & 2.07 & 31.3 & 220 & 5.853 & 295 \\
\hline 4 & 51.50 & 1.76 & 22.4 & 311 & 5.854 & 312 \\
\hline 5 & 54.03 & 1.69 & 7.5 & 222 & 5.854 & 288 \\
\hline 6 & 63.08 & 1.41 & 5.03 & 400 & 5.854 & 223 \\
\hline
\end{tabular}

trituration leads to disintegration of the ingredients into small particles; friction generates heat and the movement helps to produce the new compound. ${ }^{6}$

\section{Characterisation Techniques}

Grazing angle X-ray diffraction patterns of both the traditional Indian medicines were recorded using Shimadzu XRD-6000 diffractometer in grazing angle mode at an angle of incidence of $0.5^{\circ}$. Wide angle X-ray spectra were recorded in the $2 \theta$ range of $15^{\circ}$ to $70^{\circ}$ with a step size of $0.02^{\circ}$. Optical absorption measurements of $\beta-\mathrm{HgS}$ were carried out using spectrophotometer SPECTRO 2080 supplied by Analytical technologies limited. Photoluminescence measurements were carried out at room temperature using a Perkin Elmer LS-55 spectrometer. The Scanning electron microscope images were acquired by applying axial tilt and selecting a small portion of $\mathrm{NaCl}$ (Narikela lavan). The cluster size and surface morphology of the Narikela lavan was determined using the SEM (JEOL JSM-6390 A).

\section{RESULTS AND DISCUSSION}

\section{Structural and Surface Analysis}

The prepared Narikela lavan and kajjali (meta-cinnabar) particles were characterized by grazing angle X-ray diffraction. The observed diffraction patterns of these Indian traditional Ayurvedic drugs samples have been shown in Figure 1 and Figure 2.

Lattice parameters of $\mathrm{NaCl}$ and $\beta-\mathrm{HgS}$ are the measure of unit cell provides information about the phase of the crystal and purity. Indexing the X-ray diffraction pattern (Figure 1) consist of assigning the three Miller indices, h,k,l to each reflection. $\mathrm{NaCl}$ or Narikela Lavan belongs to face centered cubic crystal structure and hence the following equation for cubic systems was used for indexing the data. ${ }^{10}$

$$
\sin ^{2} \theta=\frac{\lambda^{2}}{4 a^{2}}\left(h^{2}+k^{2}+l^{2}\right)
$$

Where " $\theta$ " is the Bragg angle, " $\lambda$ " is the wavelength of radiation used, " $a$ " is the lattice constant and h, $k, \& l$ are the Miller indices. In the cases of end member crystalline structure, since crystal lattice parameters were known $\left(h^{2}+k^{2}+l^{2}\right)$ could easily be calculated for each reflection.

Kajjali exhibits grazing angle X-ray diffraction peaks (Figure 1) which correspond to the (111), (200), (220), (222), (311) and (400) planes of $\beta$-HgS (meta-cinnabar), and are in good agreement with the JCPDS data file no. 00-006-0261. The low intensity diffraction peaks (black red circles) denote that sulfur exists in a crystalline state, while the broad diffraction peak appears at about $26.27^{\circ}$, indicating the major crystalline characteristic of meta-cinnabar. The relative broadening of the all diffraction peaks indicates that the meta-cinnabar crystals are in nanometer size range. Based on the Debye-Scherrer equation, for the plane 111 peak with $2 \theta$ at $26.27^{\circ}$, the average particle sizes of the meta-cinnabar $(\beta-\mathrm{HgS})$ samples were approximately $37 \mathrm{~nm} .^{11}$ The free orthorhombic sulphur also found at 22.4, 23.08, 26.95, 27.6, 33.61, 35 and 47.1 degree in 2Theta. ${ }^{12}$ Grazing angle X-ray powder diffraction data along with the calculated lattice parameters and d-values for each reflection for the $\mathrm{NaCl}$ and meta-cinnabar samples are provided in Table 1 and Table 2.

Figure 3(A) represents the two dimensional SEM image of $52 \pm 5 \mathrm{~nm}$ $\mathrm{NaCl}$ nanostructures or Narikela Lavan. It is also clear from the SEM image that the smaller particles of $\mathrm{NaCl}$ are agglomerated in the form of clusters. The average particle size obtained from the SEM image is obtained as $\sim 49 \mathrm{~nm}$ that is the good agreement with grazing angle $\mathrm{X}$-ray diffraction data. The corresponding average particle size distribution histogram obtained from the SEM for Narikela Lavan sample has been shown in Figure 3(B).

\section{Optical studies}

Optical studies using optical absorption and photoluminescence techniques were undertaken to elucidate the structure-composition relationship in $\beta$-HgS. It is therefore of great interest to establish the link between the atomic level structure of mercuric sulphide polymorphs and their corresponding electronic \& optical behavior. The optical absorption spectra exhibited by $\beta$-HgS (kajjali) have been shown in Figure 4(A). According to quantum confinement theory in the material, e- in the conduction band $(\mathrm{CB})$ and holes in the valence band (VB) are spatially confined by the potential barrier of the surface. Due to confinement effect, the lowest 


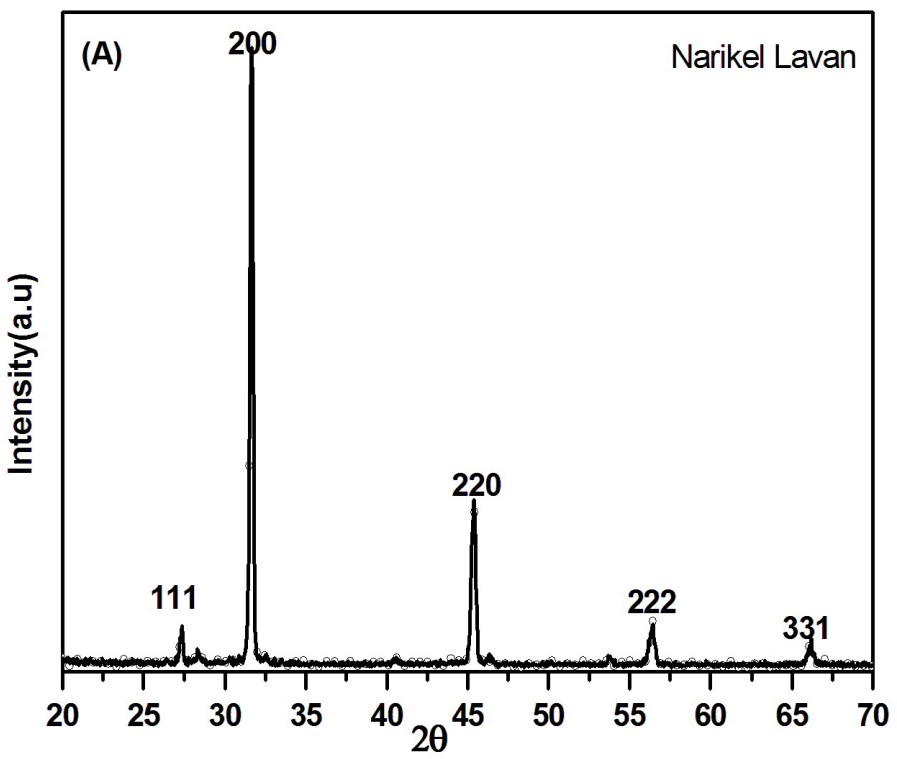

Figure 1: Grazing angle X-Ray diffraction pattern of Narikel Lavan.

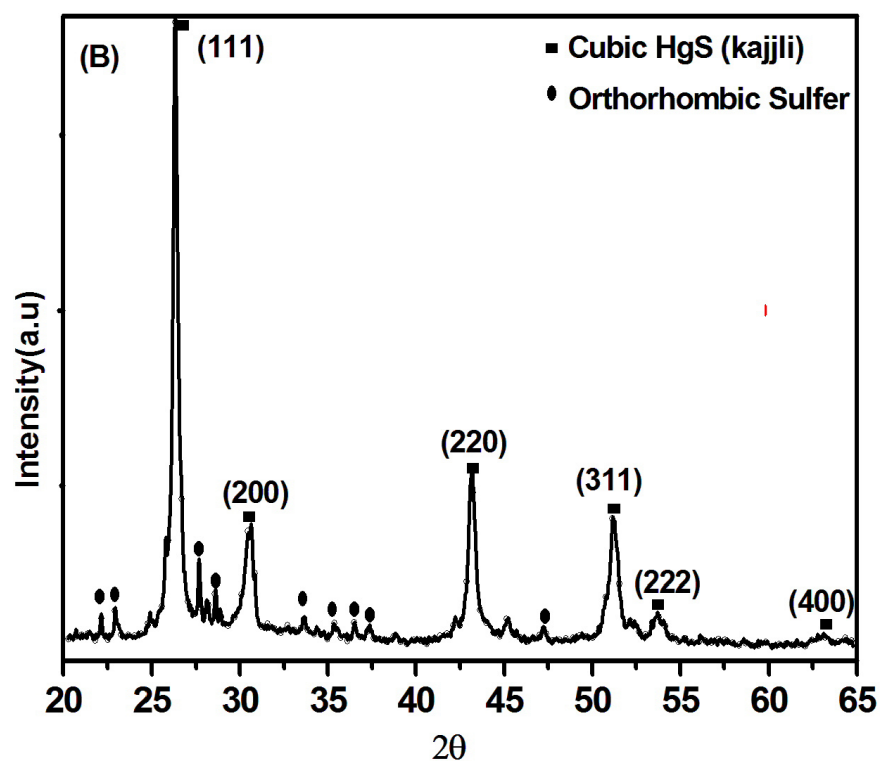

Figure 2: Grazing angle X-Ray diffraction pattern of kajjali (Metacinnabar).

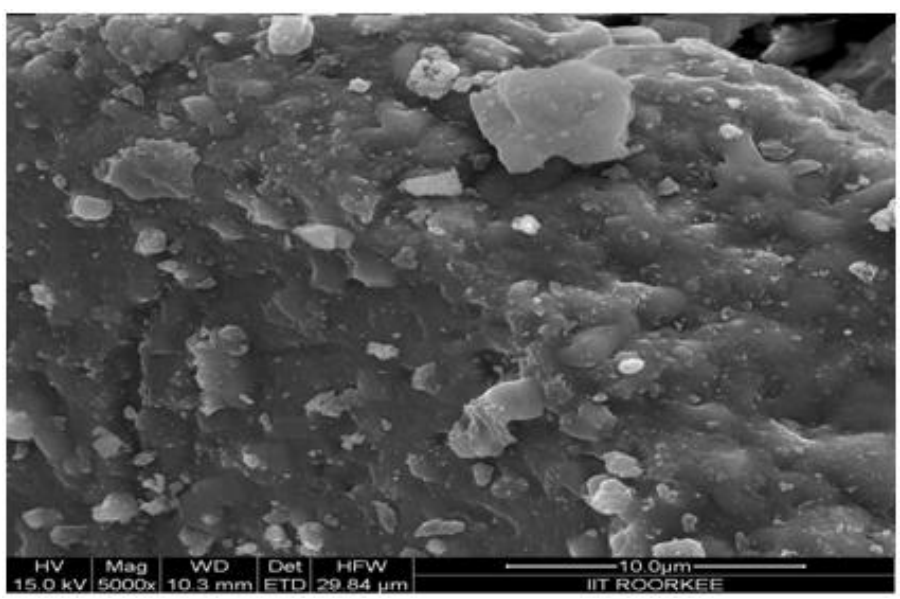

Figure 3 (a): Two dimensional SEM image of Narikela lavan.

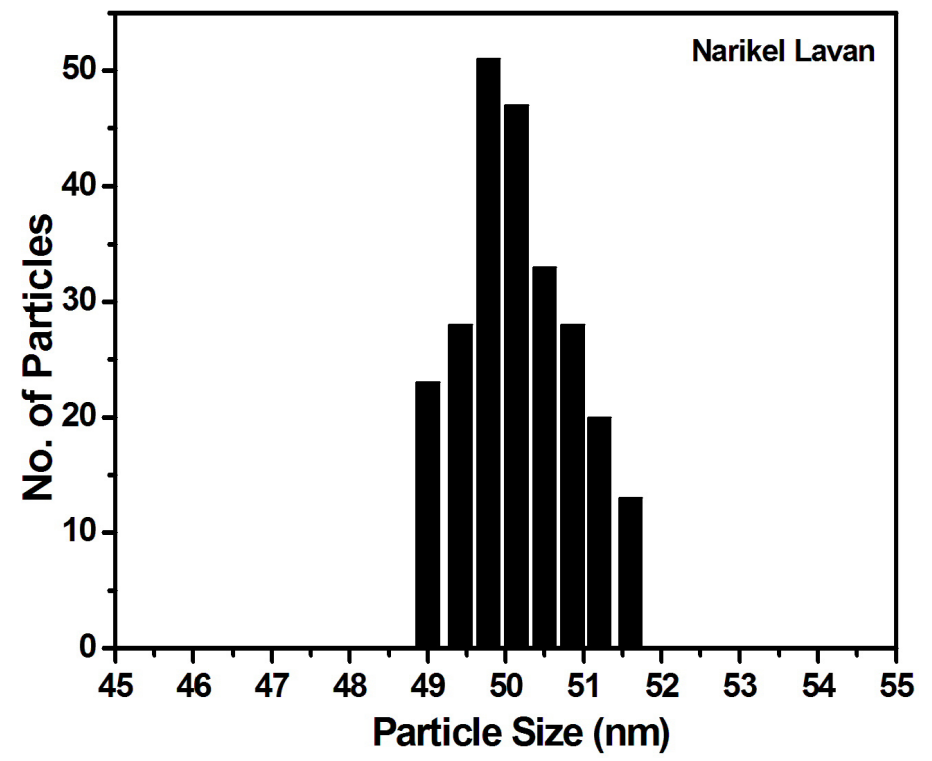

Figure 3 (b): Histogram of Narikela Lavan.

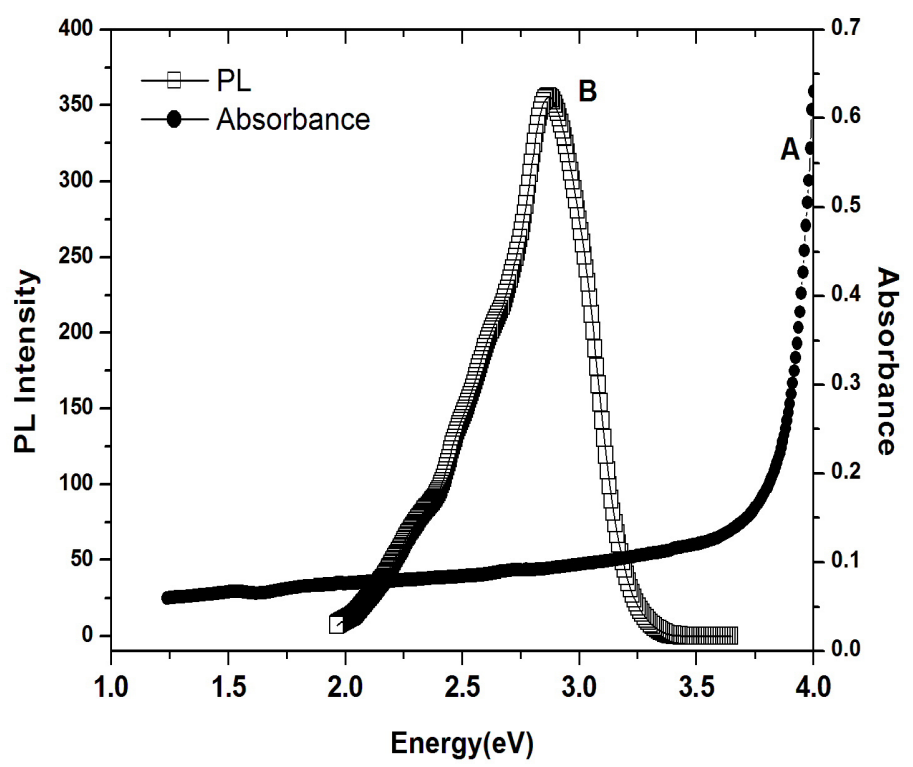

Figure 4: Optical absorption (A) and Photo luminescence (B) of kajjali (Metacinnabar).

energy optical transition from the HOMO-LUMO gap will increase in energy, effectively increasing the band-gap $\left(\mathrm{E}_{\mathrm{g}}\right)$. The shoulder of the spectra corresponds to the absorption edges in the kajjali sample, and could be used to estimate the band gap of the nano-material. ${ }^{13}$ The absorption edge $340 \mathrm{~nm}(3.64 \mathrm{eV})$ recorded for the $\beta-\mathrm{HgS}$ sample is blue shifted with respect to the corresponding bulk band edge $620 \mathrm{~nm}$ $(2.0 \mathrm{eV})$. The excitonic feature of sample is not very pronounced in $\beta$-HgS. The photoluminescence (Figure 4(B)) of the as-synthesized $\beta$-HgS were performed in order to investigate their luminescence properties. Four emission peaks have been observed for $\mathrm{HgS}$ and they are ascribed to the exciton and the trapped photo luminescence peaks. The HgS nanocrystals showed a red-shift with respect to the optical absorption edge. The observed emission peak broadening could be attributed to both the increase of the surface states and the size distribution due to the increase in surface to volume ratio for low dimensional HgS crystals. 


\section{CONCLUSION}

The Indian traditional ayurvedic medicines of mineral origin correspond to nanocrystalline materials and are also similar in their physico-chemical properties. It has been seen in different studies that the herbo-mineral formulations can be applied for targeted drug delivery as they are biocompatible, non-toxic and non-antigenic in nature. ${ }^{14}$ In present study, it has been observed that both kajjali and Narikela Lavan are highly crystalline in nature and are also showing significant optical properties. Smooth surfaces of small grains of Narikela Lavan helps in better absorp- tion. Kajjali being devoid of free radicals do not cause any harm to the body tissues and thus promises safety of the drug.

\section{ACKNOWLEDGEMENT}

I am grateful to Dr. R. J. Chaudhary, UGC-DAE-CSR (Indore), for supporting in X-ray Diffraction Characterisation.

\section{CONFLICT OF INTEREST}

The authors declare no conflict of interest.

\section{ABBREVIATIONS USED}

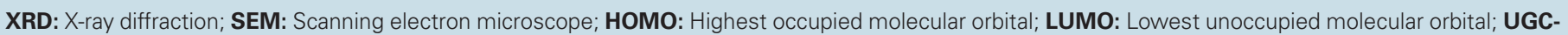
DAE-CSR: University Grant Commission-Department of Atomic Energy-Consortium for Scientific Research.

\section{ABOUT AUTHORS}

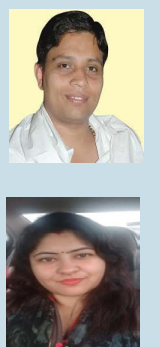

Acharya Balkrishna: Has completed his earlier education under the guidance of Late Acharya Shri Baldevji at Gurukul in Kalwa (Haryana) and obtained his postgraduate (Acharya) degree from Sampurnanand Sanskrit Vishwavidyalaya, Varanasi. He is a great visionary with multi-dimensional skills who is selflessly engaged in the service of mankind. He lives in Haridwar (Uttarakhand), India and is the founder of University of Patanjali, Patanjali Ayurved (P) Ltd., Bio Research Institute, Vedic Broadcasting Ltd., Patanjali Food and Herbal Park, Patanjali Yogpeeth Trust, Patanjali Research Foundation and Patanjali Gramodhyog Trust.

Narinder Kaur Hira: Is Research Scientist in Patanjali Natural Coloroma (P) Ltd., Haridwar (Uttarakhand), India. She graduated in Bachelor of Ayurvedic Medicine and Surgery. She has done her MD (Ay.) in Rasa-Shastra \& Bhaishajya Kalpana. Her postgraduate research focused on pharmaceutical preparation and evaluation of herbal medicine. Presently working on characterization and safety of various herbal as well as herbo-mineral medicines.

\section{REFERENCES}

1. Patwardhan B. Ayurveda and integrative medicine: Riding a tiger. Journal of Ayurveda and integrative medicine. 2010;1(1):13

2. Singh RH. Exploring issues in the development of Ayurvedic research methodology. Journal of Ayurveda and integrative medicine. 2010;1(2):91.

3. Ajanal M, Nayak S, Prasad BS, Kadam A. Adverse drug reaction and concepts of drug safety in Ayurveda: An overview. Journal of Young Pharmacists. 20130:5(4):116-20.

4. Xu L, Ye R, Zheng Y, Wang Z, Zhou P, Lin Y, Li D. Isolation of the endospermspecific LPAAT gene promoter from coconut (Cocos nucifera L.) and its functional analysis in transgenic rice plants. Plant cell reports. 2010;29(9):1061-8.

5. Devanathan R. Lavana varga in Ayurveda- A review. International Journal of Research in Ayurveda \& Pharmacy. 2010;1(2):239-48.

6. Bhatt N. Preparing Red and Black Mercury Sulphide in an Ayurvedic Setting Asian Medicine. 2013:8(1):229-38.

7. Kothari V, Kotecha K, Jain S, Kevalia J. Scientific Basis for Action of Narikela Lavan. Pharma Science Monitor. 2015;6(3):21.

8. Levy G. Gastrointestinal clearance of drugs with activated charcoal. New England Journal of Medicine. 1982;307(11):676-8.
Venkateshwar T, Dev PB, Murthy PH, Swamy GK. Physico-chemical study of different methods of parada samanya shodhana. International Journal of Ayurveda and Pharma Research. 2014;2(1):58

9. Wang B, Jin P, Yue Y, Ji S, Li Y, Luo H. Synthesis of $\mathrm{NaCl}$ single crystals with defined morphologies as templates for fabricating hollow nano/micro-structures. Rsc Advances. 2015;5(7):5072-6.

10. Xu X, Carraway ER. Sonication-Assisted Synthesis of $\beta$-Mercuric Sulfide Nanoparticles. Nanomaterials and Nanotechnology. 2012;2(Godište 2012):2-17.

11. Zhang B, Qin X, Li GR, Gao XP. Enhancement of long stability of sulfur cathode by encapsulating sulfur into micropores of carbon spheres. Energy \& Environmental Science. 2010;3(10):1531-7

12. Onwudiwe DC, Ajibade PA. ZnS, CdS and HgS nanoparticles via alkyl-phenyl dithiocarbamate complexes as single source precursors. International journal of molecular sciences. 2011;12(9):5538-51.

13. Paul S, Chugh A. Assessing the role of ayurvedic Bhasmas as ethno-nanomedicine in the metal based nanomedicine patent regime. Journal of Intellectual Property Rights. 2011;16(6):509-15. 